\title{
Doubling the power conversion efficiency in CdS/CdSe quantum dot sensitized solar cells with a ZnSe passivation layer
}

Fei Huang, ${ }^{\text {ab }}$ Juan Hou, ${ }^{\mathrm{c}}$ Qifeng Zhang, ${ }^{\mathrm{b}}$ Yuan Wang, ${ }^{\mathrm{b}}$ Robert C. Massé, ${ }^{\mathrm{b}}$ Shanglong Peng, ${ }^{\mathrm{b}}$ Huanli Wang, ${ }^{\mathrm{a}}$ Jianshe Liu, ${ }^{\mathrm{a}}$ Guozhong Cao ${ }^{* \mathrm{~b}}$

${ }^{a}$ College of Environmental Science and Engineering, Donghua University, Shanghai 201620, P.R. China

${ }^{b}$ Department of Materials and Engineering, University of Washington, Seattle, Washington 98195-2120, United States

${ }^{c}$ Key Laboratory of Ecophysics and Department of Physics, College of Science, Shihezi University, Xinjiang 832003, P.R. China

* Corresponding author.

E-mail addresses: liujianshe@dhu.edu.cn (J. Liu), gzcao@u.washington.edu (G. Cao)

\begin{abstract}
:
The surface passivation layer in quantum dot sensitized solar cells (QDSSCs) plays a very important role in preventing surface charge recombination and, thus, improving the power conversion efficiency. The present study demonstrated the introduction of a ZnSe passivation layer prepared with a successive ionic layer absorption and reaction (SILAR) method in CdS/CdSe co-sensitized solar cells, though not likely in the ideal form of a conformal overlayer, have significantly enhanced the power conversion efficiency, which was found to be far more efficient than the most widely used $\mathrm{ZnS}$
\end{abstract}


passivation layer. Not only can the ZnSe passivation layer reduce surface charge recombination, but can also enhance the light harvesting. The short-circuit current density, open-circuit voltage, fill factor, and the corresponding photovoltaic conversion efficiency were all significantly improved with the introduction of a $\mathrm{ZnSe}$ passivation layer but varied appreciably with the layer thickness. When three SILAR cycle layer was applied, the power conversion efficiency is as high as $6.4 \%$, which is almost doubled the efficiency of $3.4 \%$ for the solar cell without $\mathrm{ZnSe}$ passivation layer. For the comparison, the CdS/CdSe co-sensitized solar cells with optimum ZnS passivation layer was also fabricated, which generated a power conversion efficiency of $4.9 \%$, much lower than $6.4 \%$ of $\mathrm{ZnSe}$ passivated QDSSCs. This work demonstrated that $\mathrm{ZnSe}$ would be a good alternative to $\mathrm{ZnS}$ as a passivation material.

\section{Graphical Abstract:}

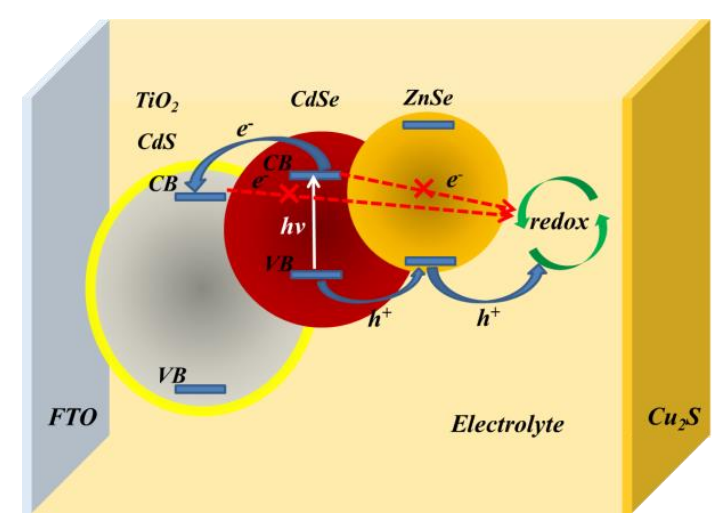

\section{Key words:}

ZnSe Passivation layer; CdS/CdSe quantum dots; Charge recombination; Light 
absorption; Quantum dot-sensitized solar cells

\section{Introduction}

Developing low cost and high performance solar cells for harvesting and converting solar energy to electricity is one of the most promising technologies to meet the imperative societal need for sustainable clean energy with minimal or no detrimental environmental impact [1]. Over the decades, many new technologies and materials have been investigated to meet the demand for low cost and highly efficient solar power conversion, and tremendous progress has been made [2-5]. For example, organic photovoltaics have demonstrated a power conversion efficiency of $12 \%$ [6] and the perovskite solar cells reached a conversion efficiency of $\sim 20 \%$ [7]. However, they both suffer from poor stability in ambient environment [8, 9]. Dye sensitized solar cells (DSSCs) have received intensive research over the past 25 years, due mainly to its insensitivity of impurities, inexpensive and simple fabrication process, and relatively high power conversion efficiency [10-12]. But the further development of DSSCs is limited by the light harvesting and the challenge of synthesis of new and low cost dyes [13]. Narrow band gap quantum dots (QDs) such as CdS [14], CdSe [15-17], $\mathrm{PbS}[18,19], \mathrm{CdTe}[20]$ and $\mathrm{Ag}_{2} \mathrm{~S}$ [21] can be used as solar harvesters to replace dyes, due to their tunable band gaps, larger extinction coefficients, multiple exciton generation (MEG) effect with single-photon absorption, and higher stability in the water and air [22, 23]. Quantum dot sensitized solar cells (QDSSCs) can be 
regarded as a derivative of dye sensitized solar cells and are promising in being next generation of photovoltaics for wide spread applications.

In spite of many efforts made on the QDSSCs with much high theoretical conversion efficiency in the past, the best power conversion efficiency remains obviously lower than that of DSSCs [11]. There are many factors that influence the performance of QDSSCs, including the electrocatalytic activity of the counter electrode, the efficiency of redox couples in electrolyte, the type of QDs and the structure of mesoporous film for photoanode. However, the relatively lower efficiency was primarily attributed to high charge recombination, mainly including the recombination between the electrons in QDs and the oxidized form of the redox couples and between the eletrons in the oxide ( for example, $\mathrm{TiO}_{2}$ ) and the oxidized form of redox couples $[3,24]$. The latter is due to the fact that it is very difficult to get a full and conformal coverage of QDs on the inner surface of mesoporous photoanode, so part of the bare photoanode $\left(\mathrm{TiO}_{2}\right.$, for example) would have direct contact with the electrolyte permitting a leakage of electrons to the electrolyte[15, 25]. When in-situ growth methods including chemical bath deposition (CBD) and successive ionic layer absorption and reaction (SILAR) have been widely used to deposit QDs directly onto photoanode to ensure the intimate contact between photoanode and QDs and the homogeneous distribution of QDs. However, the resulting QDs, particular the surface states of the QDs are far from perfect due to the low temperature processing. Such the surface states of QDs exert an appreciable but detrimental role leading to pronounced charge recombination [26], Therefore, surface passivation of the QDs as well as the 
mesoporous oxide electrode with organic and/or inorganic materials has been a critically important aspect in the QDSSCs research [24, 27].

Among all the QDs, CdS and CdSe have attracted much research attention. CdS has a higher conduction band edge than the commonly used oxides such as $\mathrm{TiO}_{2}$ and $\mathrm{ZnO}$ that forming the photoanode. The high conduction band edge of CdS may facilitate the photo excited electrons injecting into photoanode, however its wide band gap (2.25 eV in bulk) leads to limited light absorption [15]. Compared with $\mathrm{CdS}, \mathrm{CdSe}$ has a narrow band gap ( $1.7 \mathrm{eV}$ in bulk) conresponding to the wavelength of $720 \mathrm{~nm}$ in visible-light region [15]. Therefore, co-sensitization of the oxide photoanode with $\mathrm{CdS}$ and CdSe quantum dots would allow both broad light absorption and effective charge injection, and the deposition of $\mathrm{CdS}$ and $\mathrm{CdSe}$ quantum dots can be readily achieved by SILAR, CBD [28, 29], link assisted binding of the pre-synthesized colloidal QDs [30], photodeposition, and electrophoresis methods [31]. CdS/CdSe co-sensitized solar cells have been extensively studied. So far the highest PCE of $\mathrm{CdS} / \mathrm{CdSe}$ co-sensitization system with mesoporous $\mathrm{TiO}_{2}$ films as photoanodes has reached $6 \%$ [32-34], where typically a wide-band-gap semiconductor $\mathrm{ZnS}$ is coated to function as a passivation layer.

As for the passivation layer in QDSSCs, ZnS has been the most frequently studied inorganic passivation agent to reduce and prevent interfacial charge recombination $[26,35,36]$; while other inorganic materials such as $\mathrm{SiO}_{2}$ [37], $\mathrm{TiO}_{2}[38], \mathrm{PbCl}_{\mathrm{x}}$ [39] have also been reported. In addition, organic materials such as thiols [40], amines [41], and carboxylic acids [42] have also been studied to passivate the surface states of QDs 
by acting as electron or hole traps. All these works demonstrated that the passivation treatment is an effective way to improve the power conversion efficiency of QDSSCs. Recently, Zhong's group applied a $\mathrm{ZnS} / \mathrm{SiO}_{2}$ barrier coating on the $\mathrm{CdSe}_{\mathrm{x}} \mathrm{Te}_{1-\mathrm{x}}$ QD-sensitized photoanode to inhibit interfacial charge recombination as well as to improve the cell stability, with the highest power conversion efficiency of $8.55 \%$ achieved. Their result further illustrated that the suppression of charge recombination at the oxide/electrolyte interface is a very vital aspect to improve photovoltage and photocurrent of QDSSCs [43].

$\mathrm{ZnS}$ used for passivation layer is because it has a more negative minimum conduction band edge $\left(\mathrm{E}_{\mathrm{cb}}\right)$ compared to $\mathrm{CdS} / \mathrm{CdSe} \mathrm{QDs}$, and can thus prevent electron transfering from the QDs and oxide to the electrolyte. However, since the maximum valence band edge of $\mathrm{ZnS}$ is more positive than those of CdS/CdSe QDs, the use of $\mathrm{ZnS}$ for passivation layer would undesirably retard the hole transfer from QDs to electrolyte, causing reduced charge separation in QDs [36]. In order to circumvent the detrimental impact on the charge separation and injection, alternate passivation material with appropriate electronic structure is worth being explored. $\mathrm{ZnSe}$ is a good candidate, in view of its $E_{\mathrm{cb}}$ and $\mathrm{E}_{\mathrm{vb}}$ are higher than those of $\mathrm{CdS} / \mathrm{CdSe}$ QDs; such band alignment would not only prevent the electron back transfer to the electrolyte but may also facilitate the desired hole transport from the QDs to the electrolyte. Udit et al. [44] reported a thick ZnSe layer in CdSe/CdS/ZnSe type II core/intermediate/shell (C/I/S) structures facilitates electron-hole pair separation. Ahmed et al. [45] constructed CdSe/CdS/ZnSe type II core/shell structures 
in QDSSCs and demonstrated the power conversion efficiency increased from $1.86 \%$ to $3.99 \%$ with the introduction of a ZnSe layer. Zhou et al. [46] introduced a thin ZnSe layer between CdSe QDs and ZnS layer, resulting in a significantly increased photocurrent and a large enhancement in solar energy conversion efficiency. It was explained that the introduction of $\mathrm{ZnSe}$ could reduce the lattice mismatch between $\mathrm{CdSe}$ and $\mathrm{ZnS}$, which led to the suppression of defect formation at the $\mathrm{CdSe} / \mathrm{ZnS}$ interface and thus facilitated the growth of $\mathrm{ZnS}$ with enhanced quality and improved the stability of CdSe QDSSC.

Although $\mathrm{ZnSe}$ as a passivation layer has a favorable electronic configuration and has demonstrated effects on improving the power conversion efficiency in QDSSCs, the efficiency remains lower than $5 \%$ at present $[45,47,48]$. In this work, we demonstrated the effects of $\mathrm{ZnSe}$ passivation layer with approporiate coverage and thickness on the photovoltaic performance of $\mathrm{TiO}_{2} / \mathrm{CdS} / \mathrm{CdSe}$ QDSSCs in terms of light absorption, charge transport, and charge recombination. It was found that the PCE of a solar cell with three SILAR cycles deposition of ZnSe passivation layer increased from $3.4 \%$ to $6.4 \%\left(\mathrm{~V}_{\mathrm{oc}}=0.58 \mathrm{~V}, \mathrm{~J}_{\mathrm{sc}}=20.11 \mathrm{~mA} \mathrm{~cm}{ }^{-2}, \mathrm{FF}=0.55\right)$, an almost $87 \%$ enhancement compared to the solar cells without ZnSe passivating layer. For the comparison, the $\mathrm{CdS} / \mathrm{CdSe}$ co-sensitized solar cells with optimum $\mathrm{ZnS}$ passivation layer was also fabricated, which generated a power conversion efficiency of $4.9 \%$, much lower than $6.4 \%$ of $\mathrm{ZnSe}$ passivated QDSSCs. This work demonstrated that $\mathrm{ZnSe}$ would be a good alternative to $\mathrm{ZnS}$ as a passivation material. 


\section{Experimental section}

\subsection{Chemicals and material}

Titanium oxide $\left(\mathrm{TiO}_{2}\right.$, Degussa, P25), $\alpha$-terpineol $\left(\mathrm{C}_{10} \mathrm{H}_{8} \mathrm{O}, 96 \%\right.$, Sigma Aldrich), ethyl cellulose $\left(\left[\mathrm{C}_{6} \mathrm{H}_{7} \mathrm{O}_{2}\left(\mathrm{OC}_{2} \mathrm{H}_{5}\right)_{3}\right]_{\mathrm{n}}, 48.0-49.5 \%\right.$ (w/w) as ethoxyl, Sigma Aldrich), zinc acetate dihydrate $\left(\mathrm{Zn}(\mathrm{AC})_{2} \cdot 2 \mathrm{H}_{2} \mathrm{O}, \mathrm{AR}, 98.0 \%\right)$, cadmium acetate dihydrate $\left(\mathrm{Cd}(\mathrm{AC})_{2} \cdot 2 \mathrm{H}_{2} \mathrm{O}, \mathrm{AR}, 98.0 \%\right)$, cadmium nitrate tetrahydrate $\left(\mathrm{Cd}\left(\mathrm{NO}_{3}\right)_{2} \cdot 4 \mathrm{H}_{2} \mathrm{O}, \mathrm{AR}\right.$, 98.0\%), sodium sulfide $\left(\mathrm{Na}_{2} \mathrm{~S}, \mathrm{AR}, 98.0 \%\right)$, sodium borohydride $\left(\mathrm{NaBH}_{4}, \mathrm{AR}, 98.0 \%\right)$, selenium powder (Se, -200 mesh, 99.9\%), and sulfur (S, Reagent grade). brass foil (alloy 260, $0.3 \mathrm{~mm}$ thick, Alfa Aesar), hydrochloric acid (HCl, 37\%, USA), methanol $\left(\mathrm{CH}_{3} \mathrm{OH}, \geqslant 99.5 \%\right.$, Sigma Aldrich), and ethanol $\left(\mathrm{CH}_{3} \mathrm{CH}_{2} \mathrm{OH}, \geqslant 99.5 \%\right.$, Decon) were all directly used without further purification. Ultrapure deionized water was used for the preparation of all aqueous solutions.

\subsection{Preparation of Mesoporous $\mathrm{TiO}_{2}$ Films}

$\mathrm{A} \mathrm{TiO}_{2}$ paste was composed of $0.5 \mathrm{~g}$ Degussa P25 mixed with $0.25 \mathrm{~g}$ ethyl cellulose and $1.75 \mathrm{~g} \alpha$-terpineol dispersed into $5.0 \mathrm{~mL}$ ethanol after removing the ethanol under stirring. Transparent $\mathrm{TiO}_{2}$ mesoporous film was prepared via doctor blading the $\mathrm{TiO}_{2}$ paste on a clean F:SnO ${ }_{2}$-coated (FTO, 6-8 $\Omega /$ square) glass substrate. The film was then sintered at $500{ }^{\circ} \mathrm{C}$ for $30 \mathrm{~min}$ to remove impurities and improve the crystallinity. The thickness of the $\mathrm{TiO}_{2}$ film, measured with SEM was about $17 \mu \mathrm{m}$.

2.3 Growth of CdS/CdSe QDs and ZnSe passivation layer

$\mathrm{CdS}$ seed layer was first deposited by SILAR method on the surface of $\mathrm{TiO}_{2}$ 
mesoporous film to facilitate the subsequent CdSe growth. The film was first immersed into a $0.1 \mathrm{M} \mathrm{Cd}\left(\mathrm{NO}_{3}\right)_{2} \cdot 4 \mathrm{H}_{2} \mathrm{O}$ solution for $1 \mathrm{~min}$. After rinsed with methanol and dried, the film was immersed into a $0.1 \mathrm{M} \mathrm{Na} \mathrm{Na}_{2} \mathrm{~S}$ solution for another $1 \mathrm{~min}$, followed by rinsing with methanol and dring again. This process was repeated five times.

CdSe was deposited on the $\mathrm{TiO}_{2} / \mathrm{CdS}$ film through a CBD procedure. The CBD solution contains $0.1 \mathrm{M} \mathrm{Na}_{2} \mathrm{SeSO}_{3}, 0.1 \mathrm{M} \mathrm{Cd}(\mathrm{AC})_{2} \cdot 2 \mathrm{H}_{2} \mathrm{O}$, and $0.2 \mathrm{M} \mathrm{N}\left(\mathrm{CH}_{2} \mathrm{COONa}\right)_{3}$ with a volume ratio of $1: 1: 1$. The $\mathrm{TiO}_{2} / \mathrm{CdS}$ film was immersed in this solution under dark condition for $3 \mathrm{~h}$ at room temperature.

After CdSe deposition, ZnSe was deposited by a SILAR method. Briefly, 0.1 M Se source solution was prepared by mixing sodium borohydride $\left(\mathrm{NaBH}_{4}\right)$ and selenium powder in deionized water with vigorous stirring while the container was purged with $\mathrm{N}_{2}$ until it became transparent. $\mathrm{TiO}_{2} / \mathrm{CdS} / \mathrm{CdSe}$ films were first immersed in $0.1 \mathrm{M}$ $\mathrm{Zn}(\mathrm{AC})_{2} \cdot 2 \mathrm{H}_{2} \mathrm{O}$ for $2 \mathrm{~min}$ and then in $0.1 \mathrm{M} \mathrm{NaHSe}$ for $2 \mathrm{~min}$. Following each immersion, the films were rinsed with deionized water to remove excess precursors and dried before the subsequent dipping. This immersion cycle was repeated different times for the $\mathrm{ZnSe}$ layer (designated as $1 \mathrm{ZnSe}$ ). In this process Se source solution was always purged with $\mathrm{N}_{2}$.

The ZnS passivation layer with optimum thickness ( 3 SILAR cycle deposition) was prepared by a SILAR method through dipping the $\mathrm{TiO}_{2} / \mathrm{CdS} / \mathrm{CdSe}$ film in an aqueous solution containing $0.1 \mathrm{M} \mathrm{Zn}\left(\mathrm{NO}_{3}\right)_{2}$ and $0.1 \mathrm{M} \mathrm{Na}_{2} \mathrm{~S}$ for $1 \mathrm{~min}$, respectively. This process was repeated for three times. 
2.4 Electrolyte, counter electrode and device assemble

The polysulfide electrolyte was made by dissolving $1 \mathrm{M}$ Sulfur and $1 \mathrm{M}$ sodium sulfide in deionized water before each test. The counter electrode is a nanostructured $\mathrm{Cu}_{2} \mathrm{~S}$ film on brass foil, made by immersing a brass foil into $37 \% \mathrm{HCl}$ at $80{ }^{\circ} \mathrm{C}$ for 40 min, taking it out to rinse with deionized water and ethanol, dring in air, then immersing it into the freshly prepared electrolyte for $5 \mathrm{~min}$, resulting in the formation of $\mathrm{Cu}_{2} \mathrm{~S}$ on the brass foil. The device was assembled into sandwich-type using a scotch tape placed between the QDs sensitized photoanode and counter electrode.

\section{5 characterization}

Transmission electron microscopy (TEM) was carried out on a Tecnai G2 F20 TEM. The morphology of the films was characterized by scanning electron microscope (SEM, JSM-7000). The compositional EDX analysis and elemental mapping on the samples were carried out by EDX integrated in SEM (JSM-7000). The photovoltaic properties were measured using an HP 4155A programmable semiconductor parameter analyzer under AM 1.5 simulated sunlight with a power density of $100 \mathrm{~mW}$ $\mathrm{cm}^{-2}$. Optical absorption (Perkin Elmer Lambda 900 UV/VIS/IR Spectrometer) was used to study the light absorption properties of the samples. Electrochemical impedance spectroscopy (EIS) was carried out using a Solartron 1287A coupled with a Solartron 1260 FRA/impedance analyzer to investigate the electronic and ionic processes in the QDSCs. The incident photon-to-current conversion efficiency(IPCE) was carried out using 7-SCSpec response measurement system. 


\section{Results and discussion}
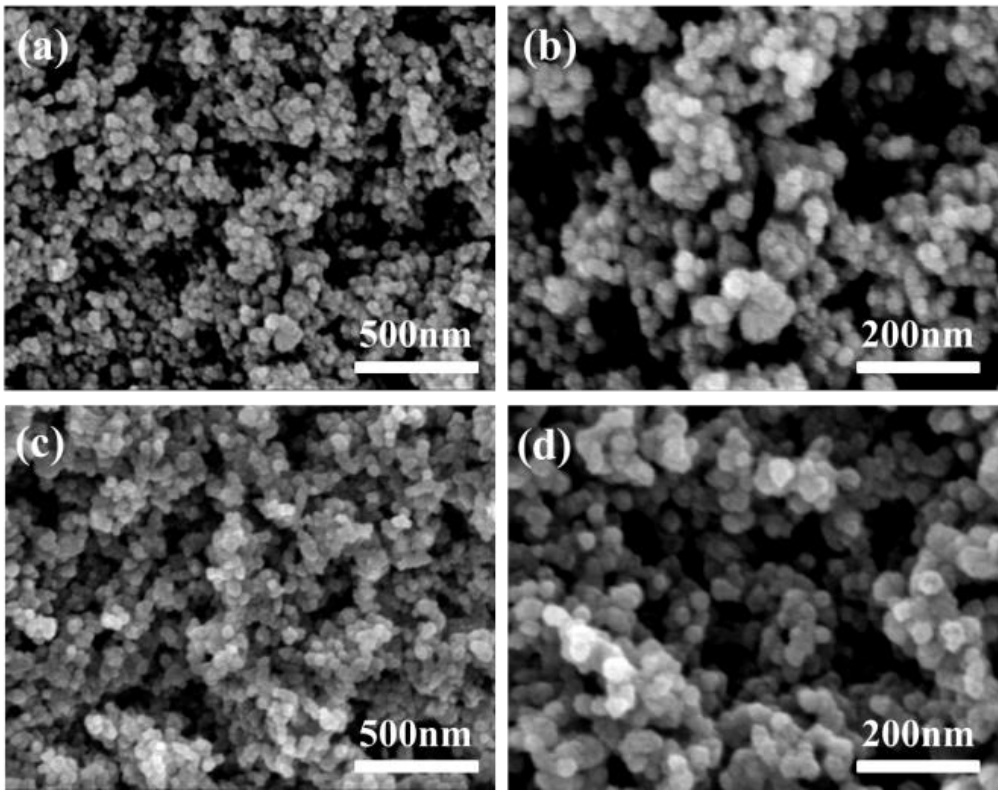

Figure $1 \mathrm{SEM}$ images of top view of $\mathrm{TiO}_{2} / \mathrm{CdS} / \mathrm{CdSe}$ photoanodes without $\mathrm{ZnSe}$ passivation layer $(a, b)$, and with three SILAR cycle deposition of ZnSe passivation layer (c, d).

Figure 1 is the SEM images representing the top view of the photoanodes. Figure 1(a) and (b) show the surface morphology of $\mathrm{TiO}_{2} / \mathrm{CdS} / \mathrm{CdSe}$ photoanodes without ZnSe passivation layer, while Figure 1(c) and (d) are the surface morphology of $\mathrm{TiO}_{2} / \mathrm{CdS} / \mathrm{CdSe}$ photoanodes with three SILAR cycle deposition of $\mathrm{ZnSe}$ passivation layer. There is no apparent change in the morphology, except a little increase in the particle size with the ZnSe passivation layer deposition, however, the exact increase in size is difficult to determine and inconclusive. 


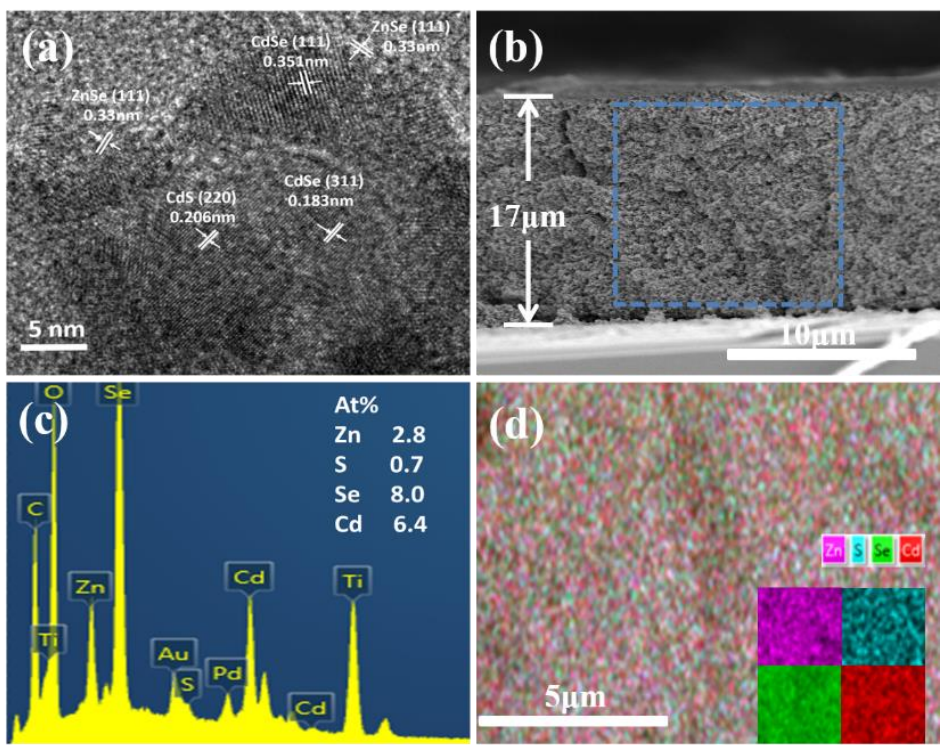

Figure 2 (a) High-resolution TEM image and (b) cross sectional SEM image of $\mathrm{TiO}_{2} / \mathrm{CdS} / \mathrm{CdSe} / 3 \mathrm{ZnSe}$ film, (c) EDX spectra based on the cross-section and (d) element distribution maps of $\mathrm{Cd}, \mathrm{S}$ and $\mathrm{Se}$ along the cross-section of $\mathrm{TiO}_{2} / \mathrm{CdS} / \mathrm{CdSe} / 3 \mathrm{ZnSe}$ mesoporous film.

Figure 2(a) is a high-resolution TEM (HRTEM) image to confirm the existence of $\mathrm{CdS}, \mathrm{CdSe}$ and $\mathrm{ZnSe}$ on the surface of mesoporous $\mathrm{TiO}_{2}$ film. Various crystalline planes are clearly observed. The lattice spacings of $0.33,0.351$ and $0.206 \mathrm{~nm}$ in the polycrystalline particle are matching well to the respective interplanar spacings of the (111) planes of cubic ZnSe and CdSe, and the (220) planes of cubic CdS. From the cross sectional view of the $\mathrm{TiO}_{2} / \mathrm{CdS} / \mathrm{CdSe} / 3 \mathrm{ZnSe}$ mesoporous film in Figure 2(b), the film thickness was approximately $17 \mu \mathrm{m}$. The EDX spectra on the cross-section of $\mathrm{TiO}_{2} / \mathrm{CdS} / \mathrm{CdSe} / 3 \mathrm{ZnSe}$ film shown in Figure 2(c), revealed the distribution of $\mathrm{CdS}$, $\mathrm{CdSe}$ and $\mathrm{ZnSe}$ QDs in the photoanode film. The atom ratios of $\mathrm{Zn}: \mathrm{S}: \mathrm{Cd}: \mathrm{Se}$ was found to be $2.8: 0.7: 8.0: 6.4$ for $\mathrm{TiO}_{2} / \mathrm{CdS} / \mathrm{CdSe} / 3 \mathrm{ZnSe}$, so the molar ratio of $\mathrm{CdS}$, CdSe and $\mathrm{ZnSe}$ can be calculated as $8: 62: 30$. This result indicates that $\mathrm{ZnSe}$ takes 
up a large portion; while CdSe QDs remains the major light absorbing phase. The cross-sectional mapping images in Figure 2(d) demonstrated that the element distributions of $\mathrm{Zn}, \mathrm{Cd}, \mathrm{S}$ and $\mathrm{Se}$ were homogeneously distributed throughout the mesoporous $\mathrm{TiO}_{2}$ films.
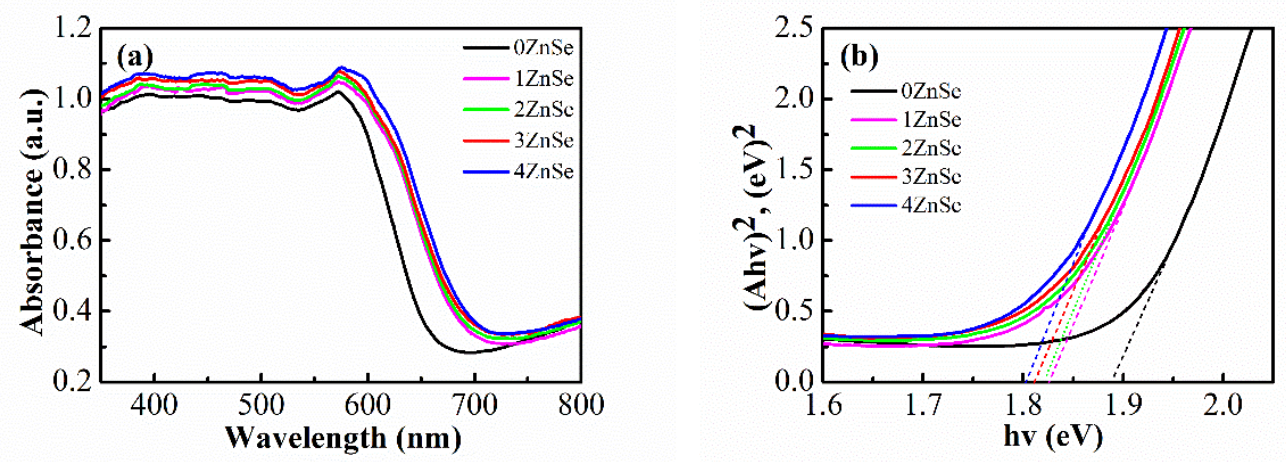

Figure 3 (a) UV-visible light absorption spectra and (b) $(\mathrm{A} h v)^{2}$ vs. $h v$ curves of $\mathrm{TiO}_{2} / \mathrm{CdS} / \mathrm{CdSe}$ films with various SILAR cycles of $\mathrm{ZnSe}$ passivation layer.

Figure 3 presents the optical absorption spectra of the $\mathrm{TiO}_{2} / \mathrm{CdS} / \mathrm{CdSe}$ films with various SILAR cycles of $\mathrm{ZnSe}$ passivation layer over the wavelengthes ranging from 350 to $800 \mathrm{~nm}$, while with the same film thickness and the same loading of CdS and CdSe QDs. There is noticeable change in both the absorbance intensity and the absorption range under the same measurement condition. The absorption showed dependence on the numbers of SILAR cycle for deposition $\mathrm{ZnSe}$ passivation layer. With increasing SILAR cycles for the deposition of $\mathrm{ZnSe}$ passivation layer the absorbance of the films increased moderately and meanwhile the light absorption edge of the films shifted to a longer wavelength in the near infrared region. In principle, the increased deposition of ZnSe would only enhance the light absorption at wavelengthes shorter than $460 \mathrm{~nm}$ considering the fact that the energy band gap of 
bulk $\mathrm{ZnSe}$ is $2.7 \mathrm{eV}$ [45]. However, Figure 3(a) shows that the introduction of $\mathrm{ZnSe}$ passivation layer enhanced the absorption at wavelengthes longer than $460 \mathrm{~nm}$. Such results were also widely reported in literatures [45, 46, 49], though no efforts have been made to elaborate and explain the cause of such enhancement. One possibility is due to the existence of excessive cadmium salts (i.e. cadmium acetate and cadmium nitrate related to the fabrication of $\mathrm{CdS}$ and $\mathrm{CdSe}$ QDs) on the surface of $\mathrm{TiO}_{2} / \mathrm{CdS} / \mathrm{CdSe}$ film; the cadmium salts react with $\mathrm{Se}^{2-}$ during the SILAR deposition of $\mathrm{ZnSe}$, leading to a further growth of the CdSe QDs and also the formation of new CdSe QDs increasing light absorption. Another possibility is due to partial overlap of the exciton wave function of $\mathrm{CdS} / \mathrm{CdSe}$ QDs and $\mathrm{ZnSe}$ passivation layer because of the interaction between the two parts $[45,49,50]$. Since the amount of cadmium salts remained on the surface of $\mathrm{TiO}_{2} / \mathrm{CdS} / \mathrm{CdSe}$ film is rather small for the formation of new $\mathrm{CdSe}$, the enhancement in absorption of the photoelectrodes likely resulted from the second reason. As shown in Figure 3(b), the band gap of the QDs was estimated by extrapolating the linear portion of the $(A h v)^{2}$ versus hv plots, according equation (1), where $A$ is the absorbance, $c$ is a constant, $v$ is the frequency and $h$ is Plank's constant $[25,51]$.

$$
(A h v)^{2}=\mathrm{c}\left(h v-E_{g}\right)
$$

As expected the calculated band gaps of the QDs are larger than the band gap of bulk CdSe $(1.74 \mathrm{eV})$ as a result of quantum confinement effect. With increasing the SILAR cycles of ZnSe passivation layer, the calculated band gap of CdS/CdSe QDs become smaller, corresponding with the red shift of the absorption edge. 
Consequently the enhanced light absorption could resulting in an increased photocurrent density $\left(\mathrm{J}_{\mathrm{sc}}\right)$.
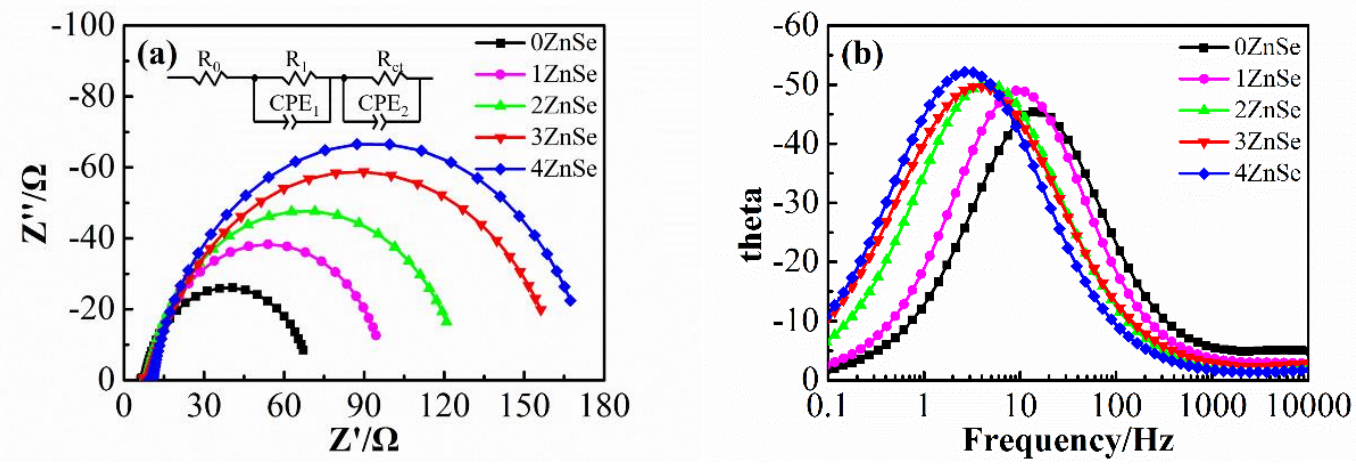

Figure 4 (a) Nyquist plots and (b) Bode plots of EIS spectra of $\mathrm{TiO}_{2} / \mathrm{CdS} / \mathrm{CdSe}$ QDSSCs with various SILAR cycles of ZnSe passivation layer recorded under dark at an applied forward bias of $-0.6 \mathrm{~V}$.

Table 1 The fitting results of the electrochemical impedance spectra of QDSSCs with photoanode coated with various SILAR deposition cycles of ZnSe passivation layer.

\begin{tabular}{llll}
\hline Samples & $\mathrm{R}_{1}(\Omega)$ & $\mathrm{R}_{\mathrm{ct}}(\Omega)$ & $\tau_{\mathrm{n}}(\mathrm{ms})$ \\
\hline $0 \mathrm{ZnSe}$ & 1.6 & 64.2 & 11.5 \\
$1 \mathrm{ZnSe}$ & 1.4 & 89.1 & 17.5 \\
$2 \mathrm{ZnSe}$ & 1.5 & 118.6 & 40.0 \\
$3 \mathrm{ZnSe}$ & 1.6 & 155.4 & 49.3 \\
$4 \mathrm{ZnSe}$ & 1.3 & 165.0 & 60.4 \\
\hline
\end{tabular}

Electrochemical impedance spectroscopy (EIS) measurements were carried out to evaluate the resistance and charge recombination process under forward bias $(-0.6 \mathrm{~V})$ and dark condition. Figure 4 shows the EIS results of the QDSSCs with various SILAR cycles of ZnSe passivation layer which were fitted with Z-view software 
based on the equivalent circuit provided in the inset of Figure 4(a). $R_{0}$ represents the resistance of FTO substrate and the resistance between FTO and $\mathrm{TiO}_{2}$. $\mathrm{R}_{1}$ represents the charge transfer resistance at counter electrode/electrolyte interface corresponding to the first and small semicircle in the Nyquist plot in the Figure 4(a). $R_{c t}$ represents the charge transfer resistance at the $\mathrm{TiO}_{2} / \mathrm{QD}$ /electrolyte interfaces and within the $\mathrm{TiO}_{2}$ films which is shown as the second and large semicircle in the Nyquist plot [16, $23,52]$.

The fitting results of the electrochemical impedance spectra are shown in Table 2. Since we used the same counter electrode and electrolyte in the test, there is no apparent difference in $\mathrm{R}_{1}$ of these QDSSCs. However, the value of $\mathrm{R}_{\mathrm{ct}}$ dramatically increased with increasing the SILAR cycles of $\mathrm{ZnSe}$ passivation layer. When four SILAR cycle ZnSe were applied, the value of $R_{c t}$ reached its maximun, significantly higher than that of the QDSSCs without ZnSe passivation layer. Because $\mathrm{R}_{\mathrm{ct}}$ represents the charge recombination resistance, the higher the value of $R_{c t}$ is, the electrons in the photoanode are harder to recombine with the electrolyte redox couple $\left(\mathrm{S}^{2-} / \mathrm{S}_{\mathrm{n}}{ }^{2-}\right)$, leading to a decreased charge recombination rate. [52, 53]. Figure 4(b) gives the bode plots of the impedance spectra, the electron lifetime can be calculated by equation (2) $[53,54]$.

$$
\tau_{n}=\frac{1}{\omega_{\min }}=\frac{1}{2 \pi f_{\min }}
$$

Where $f_{\min }$ is the peak frequency at the minimum phase angle in the Bode plot of the spectrum. The estimated electron lifetimes of the $\mathrm{TiO}_{2} / \mathrm{CdS} / \mathrm{CdSe}$ QDSSCs with various SILAR cycles of ZnSe passivation layer are listed in Table 2. When four 
SILAR cycle ZnSe passivation layer was deposited, the electron lifetime is $60.4 \mathrm{~ms}$, which is more than five times longer than that of the QDSSCs without ZnSe passivation layer (11.54 ms). It clearly reveals that introducing $\mathrm{ZnSe}$ passivation layer can prolong electron lifetime in view of reduced charge recombination at the $\mathrm{TiO}_{2} / \mathrm{QDs} /$ electrolyte interfaces. Reduced interface charge recombination is often used to explain the higher $\mathrm{V}_{\text {oc }}$ and $\mathrm{FF}[55,56]$.

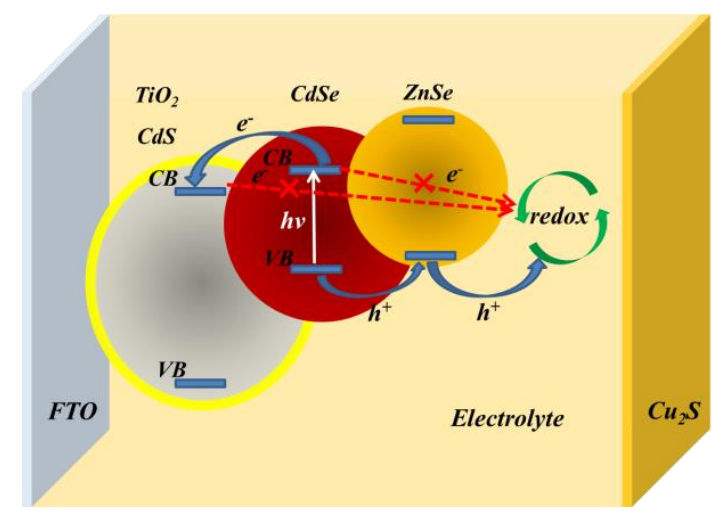

Figure 5 Schematic illustration of the charge transfer pathways in $\mathrm{TiO}_{2} / \mathrm{CdS} / \mathrm{CdSe}$ QDSSCs with ZnSe passivation layer.

The scheme of the structure and charge transfer pathways in $\mathrm{TiO}_{2} / \mathrm{CdS} / \mathrm{CdSe}$ QDSSCs with a ZnSe passivation layer is illustrated in Figure 5. Under light illumination, the $\mathrm{CdS} / \mathrm{CdSe} \mathrm{QDs}$ as sensitizer capture photons and generate electron-hole pairs which rapidly separate at the interface of QDs and $\mathrm{TiO}_{2}$ photoanode. Then electrons inject into the conduction band of $\mathrm{TiO}_{2}$, while holes are reduced by the redox couples $\left(\mathrm{S}^{2-} / \mathrm{S}_{\mathrm{n}}{ }^{2-}\right)$ in electrolyte. At the same time some charge recombination processes also take place in QDSSCs [3], such as the recombination of the excited electrons in the conduction band of QDs with $\mathrm{S}_{\mathrm{n}}{ }^{2-}$ in electrolyte and the 
recombination of electrons in the conduction band of $\mathrm{TiO}_{2}$ photoanode transfer back to react with $\mathrm{S}_{\mathrm{n}}{ }^{2-}$ in electrolyte. These recombination processes may have severe impacts on the solar cell performance. As illustrated in Figure 5, ZnSe has a more negative minimum conduction band edge $\left(\mathrm{E}_{\mathrm{cb}}\right)$ and a less positive maximum valence band edge $\left(\mathrm{E}_{\mathrm{vb}}\right)$ compared with CdS/CdSe QDs. In this structure, ZnSe as a passivation layer not only prevents the electron transfer back reaction from QDs and $\mathrm{TiO}_{2}$ photoanode to the electrolyte but also facilities hole transfer from QDs to the electrolyte. As a consequence, $\mathrm{TiO}_{2} / \mathrm{CdS} / \mathrm{CdSe}$ QDSSCs with the $\mathrm{ZnSe}$ passivation layer achieved a more efficient charge separation and a more reduced electron recombination compared to the solar cell without passivation layer. Fig. 6 shows the photocurrent density-voltage $(\mathrm{J}-\mathrm{V})$ curves of the $\mathrm{TiO}_{2} / \mathrm{CdS} / \mathrm{CdSe}$ QDSSCs with various SILAR cycles of ZnSe passivation layer measured under dark condition. Compared with the device without $\mathrm{ZnSe}$ passivation layer, the dark current decreased, with a same trend in EIS results. Which further indicates that the charge recombination process was strongly inhibited via introducing the ZnSe passivation layer. 


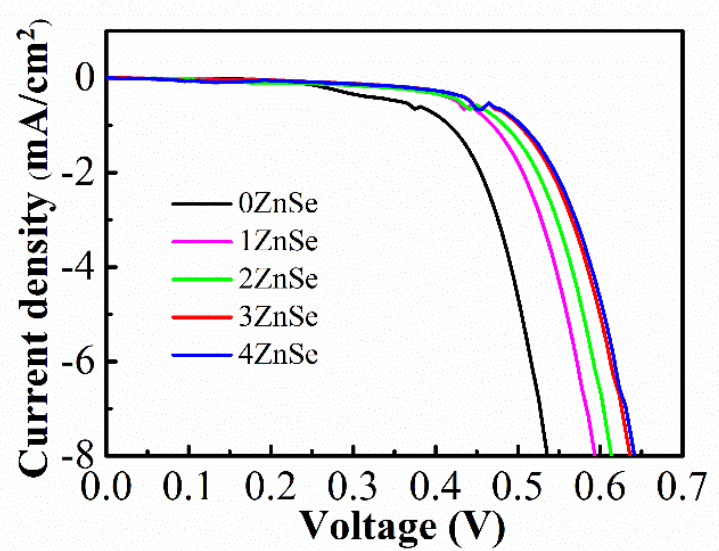

Figure 6 Photocurrent density-voltage $(\mathrm{J}-\mathrm{V})$ curves of $\mathrm{TiO}_{2} / \mathrm{CdS} / \mathrm{CdSe}$ QDSSCs with various SILAR cycles of $\mathrm{ZnSe}$ passivation layer measured under dark condition.

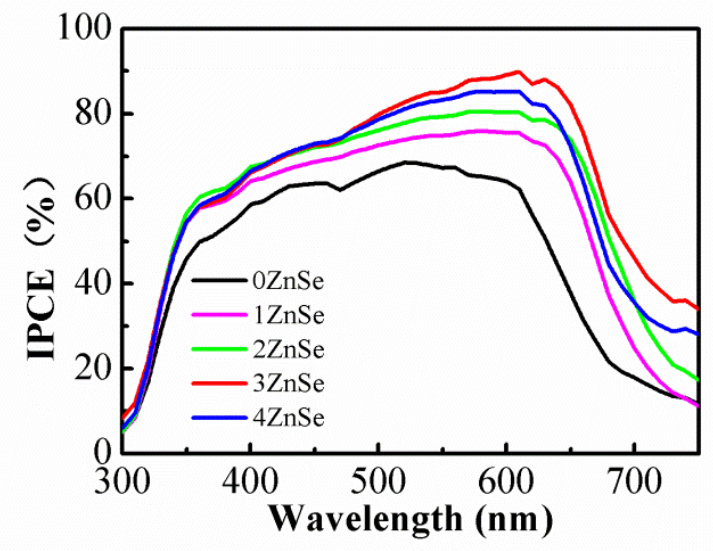

Figure 7 Incident photon-to-current conversion efficiency (IPCE) spectra of $\mathrm{TiO}_{2} / \mathrm{CdS} / \mathrm{CdSe}$ QDSSCs with various SILAR cycles of ZnSe passivation layer.

To evaluate the light absorption and electron generation characteristics, the incident photon-to-current conversion efficiency (IPCE, or external quantum efficiency, EQE ) of QDSSCs with various SILAR cycles of ZnSe passivation layer as a function of wavelength are shown as Figure 7. The maximum IPCE of $\mathrm{TiO}_{2} / \mathrm{CdS} / \mathrm{CdSe}$ QDSSCs reached $90 \%$ at $610 \mathrm{~nm}$ when three SILAR cycle ZnSe passivation layer was deposited, about $31 \%$ improvement compared with the maximum IPCE of $68 \%$ at $520 \mathrm{~nm}$ for 
$\mathrm{CdS} / \mathrm{CdSe}$ sensitized solar cells without $\mathrm{ZnSe}$ passivation layer, indicating the excellent energy conversion efficiency. IPCE can be estimated by the following equation: ${ }^{57}$

$$
I P C E=\text { ? }_{L H E} \times ?_{c t} \times ?_{c c}
$$

" $\eta_{\text {LHE }} "$ is light harvesting efficiency, $" \eta_{\mathrm{ct}} "$ is charge transfer efficiency, and $" \eta_{\mathrm{cc}} "$ is charge collection efficiency. " $\eta_{\mathrm{LHE}} "$ of the QDSSCs is consistent with the light absorption of the photoelectrodes. From the results of UV-visible spectra (as shown in Figure 3), the absorption of photoelectrodes with $\mathrm{ZnSe}$ passivation layer is much higher than that of the photoelectrodes without $\mathrm{ZnSe}$ passivation layer, indicating a higher $\eta_{\text {LHE }}$ is attained. The charge transfer efficiency " $\eta_{\mathrm{ct}}$ " is mainly determined by the energy level difference between the conduction band edge of QDs and the photoanode. The photoexcited electrons would transfer from high conduction band to the low conduction band, the difference in energy level is the driving force for charge transfer. Theoretically, the conduction band edge of CdS/CdSe QDs is over $200 \mathrm{mV}$ higher than that of $\mathrm{TiO}_{2}$, this will be sufficient to drive charge transfer from QDs to $\mathrm{TiO}_{2}[45,58]$. The charge collection efficiency $" \eta_{\mathrm{cc}} "$ is related to the charge recombination in solar cells; the deposition of $\mathrm{ZnSe}$ passivation layer can enhance the recombination resistance and prolong the electron lifetime. The reduced dark current density is also indicative of reduced charge recombination. These results are consistent with the enhancement of " $\eta_{\mathrm{cc}}$ ". The enhancement of light absorption and the decrease in charge recombination collectively contribute to the improved quantum efficiency. 

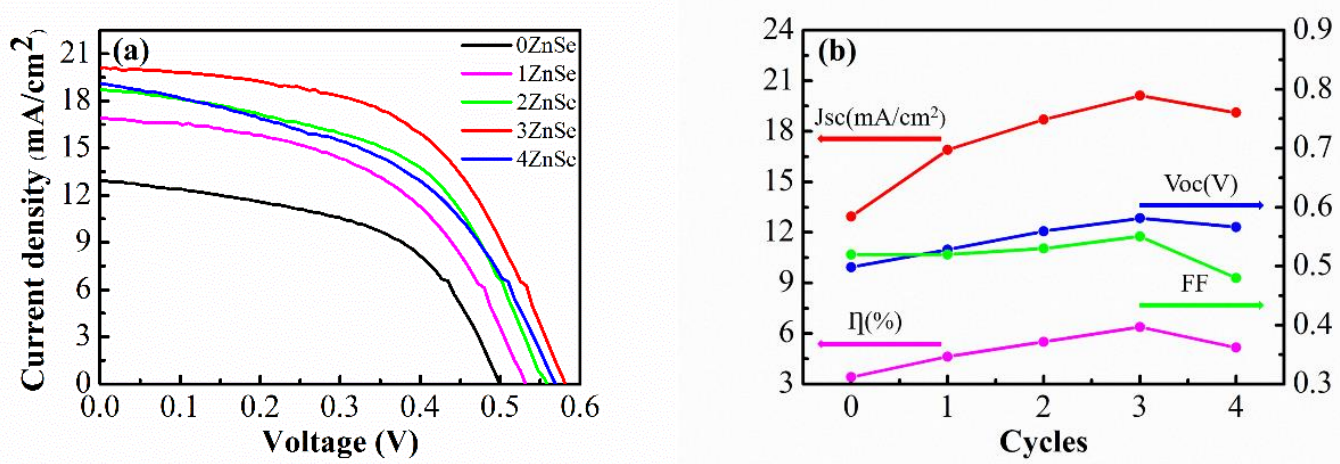

Figure 8 Photocurrent density-voltage $(\mathrm{J}-\mathrm{V})$ curves of $\mathrm{TiO}_{2} / \mathrm{CdS} / \mathrm{CdSe}$ QDSCs with various $\mathrm{ZnSe}$ passivation layer measured under AM 1.5, $100 \mathrm{~mW} / \mathrm{cm}^{2}$ sunlight.

Figure 8(a) shows the photocurrent density-voltage (J-V) characteristics of $\mathrm{TiO}_{2} / \mathrm{CdS} / \mathrm{CdSe}$ QDSSCs with various SILAR cycles of ZnSe passivation layer obtained under one Sun (AM 1.5, $100 \mathrm{~mW} / \mathrm{cm}^{2}$ ) illumination. The performance parameters of different solar cell devices are summarized in Table 2. When only CdS/CdSe QDs loading on bare $\mathrm{TiO}_{2}$ film, the device generated a short circuit current density $\left(\mathrm{J}_{\mathrm{sc}}\right)$ of $12.94 \mathrm{~mA} \mathrm{~cm}{ }^{-2}$, an open circuit voltage $\left(\mathrm{V}_{\mathrm{oc}}\right)$ of $0.498 \mathrm{~V}$, and a fill factor (FF) of 0.52 , yielding a power conversion efficiency $(\eta)$ of $3.42 \%$. When $\mathrm{ZnSe}$ passivation layer was deposited, the $\mathrm{V}_{\mathrm{oc}}, \mathrm{J}_{\mathrm{sc}}$ and $\mathrm{FF}$ all greatly increased, with three SILAR cycle ZnSe deposition the maximam values reached $20.11 \mathrm{~mA} \mathrm{~cm}^{-2}, 0.581 \mathrm{~V}$, and 0.55 , respectively and the highest power conversion efficiency of $6.39 \%$, which is much higher than the power conversion efficiency of $4.91 \%$ with a $\mathrm{ZnS}$ passivation layer. It is worth noting that the performance decreased with a further increase of the $\mathrm{ZnSe}$ deposition cycle. The changing trend of $\mathrm{V}_{\mathrm{oc}}, \mathrm{J}_{\mathrm{sc}}, \mathrm{FF}$ and $\eta$ are demonstrated in Figure 8(b), all these four parameters showed an increase initially with the increasing 
ZnSe SILAR cycles. When four SILAR cycle ZnSe passivation layer was deposited, all the performance parameters decreased, especially the FF and PCE dramatically decreased to 0.48 and $5.18 \%, \mathrm{~J}_{\mathrm{sc}}$ and $\mathrm{V}_{\mathrm{oc}}$ also have a noticeable decrease. This scenario can be explained that the increased thickness of $\mathrm{ZnSe}$ passivation layer would increase the charge transfer resistance and reduce charge recombination [44, 59]; however, a too thick passivation layer would instead hinder the electrons in electrolyte from entering the QDs efficiently to get the photo-excited QDs reduced, leading to an increase in the recombination of electron-hole pairs within the QDs and between the electrons in $\mathrm{TiO}_{2}$ with the holes in the QDs, eventually resulting in solar cell efficiency decrease as observed in the case of four cycle ZnSe passivation layer applied. The solar cell I-V result is in agreement with the UV-vis and IPCE characterizations, where the photoelectrode film with four SILAR cycle ZnSe passivation layer gives rise to higher optical absorption but decreased photon-to-current conversion efficiency compared to that with three SILAR cycle ZnSe passivation layer.

Table 2 Photovoltaic properties obtained from the $\mathrm{J}-\mathrm{V}$ curves with various $\mathrm{ZnSe}$ passivation layer and with three SILAR cycle $\mathrm{ZnS}$ passivation layer.

\begin{tabular}{lllll}
\hline Samples & $\mathrm{V}_{\text {oc }}(\mathrm{V})$ & $\mathrm{J}_{\mathrm{sc}}\left(\mathrm{mA} \mathrm{cm}^{-2}\right)$ & $\mathrm{FF}$ & $\square(\%)$ \\
\hline $0 \mathrm{ZnSe}$ & 0.50 & 12.94 & 0.52 & 3.42 \\
$1 \mathrm{ZnSe}$ & 0.53 & 16.90 & 0.52 & 4.63 \\
$2 \mathrm{ZnSe}$ & 0.56 & 18.70 & 0.53 & 5.51 \\
$3 \mathrm{ZnSe}$ & 0.58 & 20.11 & 0.55 & 6.39 \\
$4 \mathrm{ZnSe}$ & 0.57 & 19.12 & 0.48 & 5.18 \\
\hline
\end{tabular}




\begin{tabular}{lllll}
\hline $3 \mathrm{ZnS}$ & 0.55 & 15.71 & 0.57 & 4.91 \\
\hline
\end{tabular}

\section{Conclusions}

Introduction of ZnSe passivation layer to $\mathrm{TiO}_{2} / \mathrm{CdS} / \mathrm{CdSe}$ QDSSCs by a SILAR method has been demonstrated to be an efficient and promising approach to significantly improve the power conversion efficiency. The EDX composition mapping confirmed the molar ratio of $\mathrm{CdS}$, $\mathrm{CdSe}$ and $\mathrm{ZnSe}$ and homogeneous distribution of elemental cadmium, selenium, zinc and sulfur. The UV-vis, EIS and IPCE investigation of the $\mathrm{TiO}_{2} / \mathrm{CdS} / \mathrm{CdSe}$ QDSSCs with varying numbers of $\mathrm{ZnSe}$ SILAR cycles showed: (a) enhanced light absorption in both spectrum width and intensity, and (b) significantly reduced charge recombination. The performance of $\mathrm{TiO}_{2} / \mathrm{CdS} / \mathrm{CdSe}$ QDSSCs is found to be dependent on the thickness of $\mathrm{ZnSe}$ passivation layer. With three SILAR cycle deposition of ZnSe passivation layer, the $\mathrm{TiO}_{2} / \mathrm{CdS} / \mathrm{CdSe}$ QDSSC achieved a highest power conversion efficiency of $6.4 \%$, in sharp contrast to the efficiency of $3.4 \%$ when without $\mathrm{ZnSe}$ passivation layer and the efficiency of $4.9 \%$ with $\mathrm{ZnS}$ passivation layer.

\section{Acknowledgments}

This work was financially supported by the National Science Foundation (NSF, DMR 1505902) and Fei Huang would also like to acknowledge the scholarship by China Scholarship Council for the scholarship. This work was also supported by National Natural Science Foundations of China (No. 21377023 and No. 51362026). 


\section{References}

[1] N. S. Lewis, Science 315 (2007) 798-801.

[2] D. A. Baharoon, H. A. Rahman, W. Z. W. Omar and S. O. Fadhl, Renew. Sustain. Energy Rev. 41 (2015) 996-1027.

[3] J. Tian and G. Cao, J. Phys. Chem. Lett. 6 (2015) 1859-1869.

[4] D. Zhang, W. C. H. Choy, F. Xie, W. E. I. Sha, X. Li, B. Ding, K. Zhang, F. Huang and Y. Cao, Adv. Funct. Mater. 23 (2013) 4255-4261.

[5] J. Burschka, N. Pellet, S.-J. Moon, R. Humphry-Baker, P. Gao, M. K. Nazeeruddin and M. Graetzel, Nature 2013, 499, 316-320.

[6] M. A. Green, K. Emery, Y. Hishikawa, W. Warta and E. D. Dunlop, Prog. Photovolt: Res. Appl. 23 (2015) 1-9.

[7] N. J. Jeon, J. H. Noh, W. S. Yang, Y. C. Kim, S. Ryu, J. Seo and S. I. Seok, Nature 517 (2015) 476-480.

[8] G. Niu, X. Guo and L. Wang, J. Mater. Chem. A 3 (2015) 8970-8980.

[9] M. Jorgensen, K. Norrman, S. A. Gevorgyan, T. Tromholt, B. Andreasen and F. C. Krebs, Adv. Mater. 24 (2012) 580-612.

[10] Q. Zhang, C. S. Dandeneau, X. Zhou and G. Cao, Adv. Mater. 21 (2009) 4087-4108.

[11] S. Mathew, A. Yella, P. Gao, R. Humphry-Baker, B. F. E. Curchod, N. Ashari-Astani, I. Tavernelli, U. Rothlisberger, M. K. Nazeeruddin and M. Graetzel, Nat. Chem. 6 (2014) 242-247. 
[12] M. Gratzel, Inorg. Chem. 44 (2005) 6841-6851.

[13] E. Lee, C. Kim and J. Jang, Chem. Eur. J. 19 (2013) 10280-10286.

[14] W.-T. Sun, Y. Yu, H.-Y. Pan, X.-F. Gao, Q. Chen and L.-M. Peng, J. Am. Chem. Soc. 130 (2008) 1124-1125.

[15] Y.-L. Lee and Y.-S. Lo, Adv. Funct. Mater. 19 (2009) 604-609.

[16] R. Zhou, H. Niu, Q. Zhang, E. Uchaker, Z. Guo, L. Wan, S. Miao, J. Xu and G. Cao, J. Mater. Chem. A 3 (2015) 12539-12549.

[17] N. Fuke, L. B. Hoch, A. Y. Koposov, V. W. Manner, D. J. Werder, A. Fukui, N. Koide, H. Katayama and M. Sykora, Acs Nano 4 (2010) 6377-6386.

[18] T. Kawawaki, H. Wang, T. Kubo, K. Saito, J. Nakazaki, H. Segawa and T. Tatsuma, Acs Nano 9 (2015) 4165-4172.

[19] G.-H. Kim, B. Walker, D. Zhitomirsky, J. Heo, S.-J. Ko, J. Park, E. H. Sargent and J. Y. Kim, Nano Energy 13 (2015) 491-499.

[20] J. H. Bang and P. V. Kamat, ACS nano 3 (2009) 1467-1476.

[21] A. Tubtimtae, K.-L. Wu, H.-Y. Tung, M.-W. Lee and G. J. Wang, Electrochem. Commun. 12 (2010) 1158-1160.

[22] V. Gonzalez-Pedro, X. Xu, I. Mora-Sero and J. Bisquert, Acs Nano 4 (2010) 5783-5790.

[23] X.-Y. Yu, J.-Y. Liao, K.-Q. Qiu, D.-B. Kuang and C.-Y. Su, Acs Nano 5 (2011) 9494-9500.

[24] I. Mora-Sero, S. Gimenez, F. Fabregat-Santiago, R. Gomez, Q. Shen, T. Toyoda and J. Bisquert, Acc. Chem. Res. 42 (2009) 1848-1857. 
[25] J. Tian, R. Gao, Q. Zhang, S. Zhang, Y. Li, J. Lan, X. Qu and G. Cao, J. Phys. Chem. C 116 (2012) 18655-18662.

[26] L. J. Diguna, Q. Shen, J. Kobayashi and T. Toyoda, Appl. Phys. Lett. 91 (2007) 023116.

[27] J. Huang, B. Xu, C. Yuan, H. Chen, J. Sun, L. Sun and H. Agren, Acs Appl. Mater. Interfaces 6 (2014) 18808-18815.

[28] P. K. Santra and P. V. Kamat, J. Am. Chem. Soc. 134 (2012) 2508-2511.

[29] M. A. Becker, J. G. Radich, B. A. Bunker and P. V. Kamat, J. Phys. Chem. Lett. 5 (2014) $1575-1582$.

[30] M. E. Kern and D. F. Watson, Langmuir 30 (2014) 13293-13300.

[31] H. Tada, M. Fujishima and H. Kobayashi, Chem. Soc. Rev. 2011, 40, 4232-4243.

[32] J. Tian, L. Lv, C. Fei, Y. Wang, X. Liu and G. Cao, J. Mater. Chem. A 2 (2014) 19653-19659.

[33] Y. Bai, C. Han, X. Chen, H. Yu, X. Zong, Z. Li and L. Wang, Nano Energy 13 (2015) 609-619.

[34] Y.-F. Xu, W.-Q. Wu, H.-S. Rao, H.-Y. Chen, D.-B. Kuang and C.-Y. Su, Nano Energy 11 (2015) 621-630.

[35] S. Hachiya, Q. Shen and T. Toyoda, J. Appl. Phys. 111 (2012) 104315.

[36] N. Guijarro, J. M. Campina, Q. Shen, T. Toyoda, T. Lana-Villarreal and R. Gomez, Phys. Chem. Chem. Phys. 13 (2011) 12024-12032.

[37] Z. Liu, M. Miyauchi, Y. Uemura, Y. Cui, K. Hara, Z. Zhao, K. Sunahara and A. 
Furube, Appl. Phys. Lett. 96 (2010) 233107.

[38] M. Shalom, S. Dor, S. Ruhle, L. Grinis and A. Zaban, J. Phys. Chem. C 113 (2009) 3895-3898.

[39] W. K. Bae, J. Joo, L. A. Padilha, J. Won, D. C. Lee, Q. Lin, W.-k. Koh, H. Luo, V. I. Klimov and J. M. Pietryga, J. Am. Chem. Soc. 134 (2012) 20160-20168.

[40] D. A. R. Barkhouse, A. G. Pattantyus-Abraham, L. Levina and E. H. Sargent, Acs Nano 2 (2008) 2356-2362.

[41] C. Bullen and P. Mulvaney, Langmuir 22 (2006) 3007-3013.

[42] F. P. Zamborini, J. F. Hicks and R. W. Murray, J. Am. Chem. Soc. 122 (2000) 4514-4515.

[43] K. Zhao, Z. Pan, I. Mora-Sero, E. Canovas, H. Wang, Y. Song, X. Gong, J. Wang, M. Bonn, J. Bisquert and X. Zhong, J. Am. Chem. Soc. 137 (2015) $5602-5609$.

[44] U. Soni, A. Pal, S. Singh, M. Mittal, S. Yadav, R. Elangovan and S. Sapra, Acs Nano 8 (2014) 113-123.

[45] R. Ahmed, L. Zhao, A. J. Mozer, G. Will, J. Bell and H. Wang, J. Phys. Chem. C 119 (2015) 2297-2307.

[46] C. Liu, L. Mu, J. Jia, X. Zhou and Y. Lin, Electrochim. Acta 111 (2013) 179-184.

[47] J. Y. Chang, L. F. Su, C. H. Li, C. C. Chang and J. M. Lin, Chem. Commun. 48 (2012) 4848-4850.

[48] J.-Y. Chang, J.-M. Lin, L.-F. Su and C.-F. Chang, Acs Appl. Mater. Interfaces 5 
(2013) 8740-8752.

[49] D. V. Talapin, I. Mekis, S. Gotzinger, A. Kornowski, O. Benson and H. Weller, J. Phys. Chem. B 108 (2004) 18826-18831.

[50] B. O. Dabbousi, J. RodriguezViejo, F. V. Mikulec, J. R. Heine, H. Mattoussi, R. Ober, K. F. Jensen and M. G. Bawendi, J. Phys. Chem. B 101 (1997) 9463-9475.

[51] J. Tian, Q. Zhang, L. Zhang, R. Gao, L. Shen, S. Zhang, X. Qu and G. Cao, Nanoscale 5 (2013) 936-943.

[52] K. Yan, W. Chen and S. Yang, J. Phys. Chem. C 117 (2013) 92-99.

[53] R. Kern, R. Sastrawan, J. Ferber, R. Stangl and J. Luther, Electrochim. Acta 47 (2002) 4213-4225.

[54] J. Tian, Q. Zhang, E. Uchaker, R. Gao, X. Qu, S. Zhang and G. Cao, Energy Environ. Sci. 6 (2013) 3542.

[55] R. Gao, J. Tian, Z. Liang, Q. Zhang, L. Wang and G. Cao, Nanoscale 5 (2013) 1894-1901.

[56] J. Tian, E. Uchaker, Q. Zhang and G. Cao, ACS Appl. Mater. Interfaces 6 (2014) 4466-4472.

[57] S. S. Shin, J. S. Kim, J. H. Suk, K. D. Lee, D. W. Kim, J. H. Park, I. S. Cho, K. S. Hong and J. Y. Kim, Acs Nano 7 (2013) 1027-1035.

[58] L. Yang, C. McCue, Q. Zhang, E. Uchaker, Y. Mai and G. Cao, Nanoscale 7 (2015) 3173-3180.

[59] S. A. Ivanov and M. Achermann, Acs Nano 4 (2010) 5994-6000. 


\section{Personal portraits:}

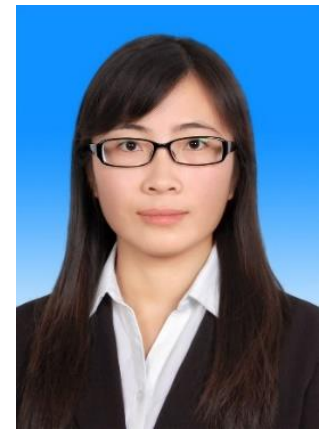

Fei Huang is a PhD candidate under the supervision of Prof. Jianshe Liu at Donghua University, China. She is currently a visiting student under the supervision of Prof.

Guozhong Cao at University of Washington, Seattle. Her recent research mainly focuses on interface modification, photoanode material synthesis of quantum dot sensitized solar cells.

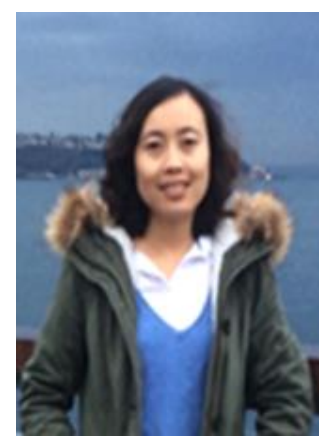

Juan Hou earned her PhD degree from University of Chinese Academy of Sciences in 2003. Currently she is an assistant professor in college of science at Shihezi University, China. Her current research focuses on quantum dots and their application in photovoltaic conversion devices.

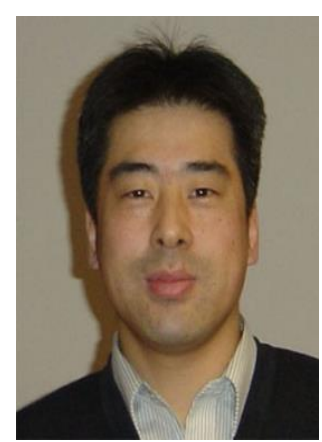


Qifeng Zhang is currently working at University of Washington as a Research Assistant Professor. His research interests involve engineering applications of nano-structured materials on electrical devices including solar cells, UV light-emitting diodes (LEDs), eld-effect transistors (FETs), and gas sensors. His current research focuses on the synthesis of nanomaterials and the application of nanomaterials in electronic and optoelectronic devices, such as dye-sensitized solar cells (DSCs) and organic/inorganic hybrid solar cells.

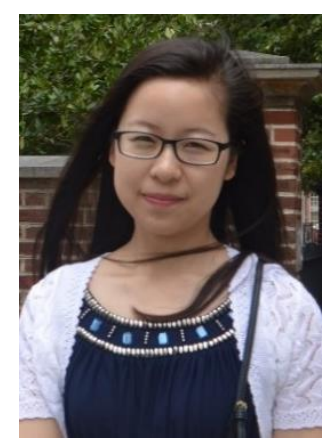

Yuan Wang is working for her Ph.D. degree in state key laboratory of organic-inorganic composites, Beijing University of Chemical Technology. Her current research is focused on development of visible-light-responsive photocatalysts and Quantum dot sensitized solar cells.

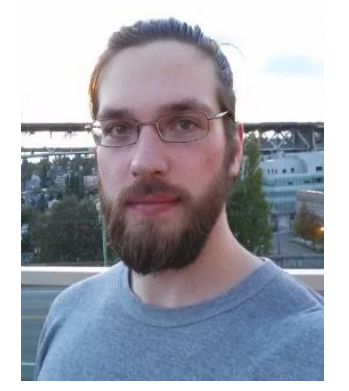

Robert C. Massé received his BSc degree from the University of Wisconsin-Madison. $\mathrm{He}$ is currently a PhD student at the University of Washington under the supervision of Prof. Guozhong Cao. His research interests include the electrochemistry and 
characterization of energy storage materials for alkali-ion batteries.

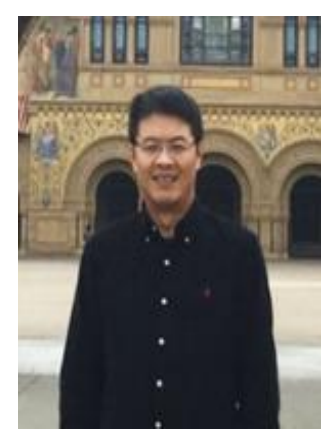

Shanglong Peng is an associate professor of school of physical science and technology at Lanzhou University. His current research is focused mainly on new energy materials and devices including Si-based inorganic-organic hybrid solar cells, quantum dot sensitized solar cells and supercapacitor. And he has published over 50 papers.

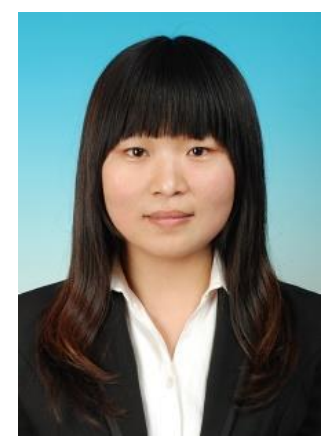

Huanli Wang is now working as a Lecturer in Qingdao Technological University. She obtained her PhD degree from Donghua University, in 2015. From 2013 to 2014, she worked in Professor Nicholas A. Kotov's group as a visiting student at University of Michigan, USA. Her current research concentrates on the synthesis and properties of nanostructured photocatalytic materials. 


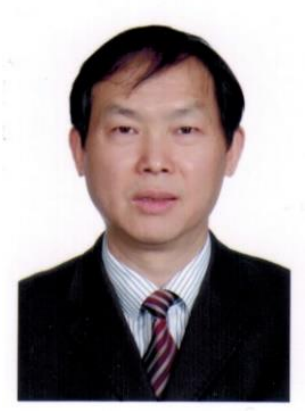

Jianshe Liu is Dean of the college of environmental science and engineering, and Professor of environmental science at Donghua University. He has published more than 100 peer-reviewed articles. His recent research mainly focuses on environmental biotechnology, advanced oxidation technology, functional nanostructured materials and their applications in photocatalysis and solar cells.

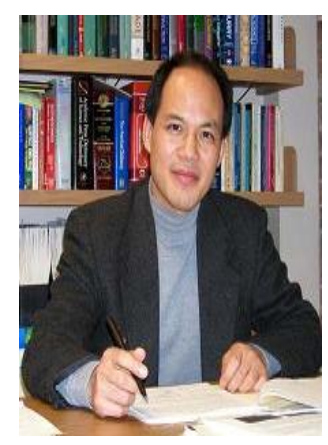

Guozhong Cao is Boeing-Steiner Professor of materials science and engineering, professor of chemical engineering, and adjunct professor of mechanical engineering at the University of Washington, and also a professor at Beijing Institute of Nanoenergy and Nanosystems, Chinese Academy of Sciences and Dalian University of Technology. His current research is focused on chemical processing of nanomaterials for energy related applications including solar cells, rechargeable batteries, supercapacitors, and hydrogen storage. 